\title{
TU/e EN⿴HONE

\section{Formation of InAs wetting layers studied by cross-sectional scanning tunneling microscopy}

\section{Citation for published version (APA):}

Offermans, P., Koenraad, P. M., Nötzel, R., Wolter, J. H., \& Pierz, K. (2005). Formation of InAs wetting layers studied by cross-sectional scanning tunneling microscopy. Applied Physics Letters, 87(11), 111903-1/3.

[111903]. https://doi.org/10.1063/1.2042543

DOI:

$10.1063 / 1.2042543$

Document status and date:

Published: 01/01/2005

\section{Document Version:}

Publisher's PDF, also known as Version of Record (includes final page, issue and volume numbers)

\section{Please check the document version of this publication:}

- A submitted manuscript is the version of the article upon submission and before peer-review. There can be important differences between the submitted version and the official published version of record. People interested in the research are advised to contact the author for the final version of the publication, or visit the $\mathrm{DOI}$ to the publisher's website.

- The final author version and the galley proof are versions of the publication after peer review.

- The final published version features the final layout of the paper including the volume, issue and page numbers.

Link to publication

\section{General rights}

Copyright and moral rights for the publications made accessible in the public portal are retained by the authors and/or other copyright owners and it is a condition of accessing publications that users recognise and abide by the legal requirements associated with these rights.

- Users may download and print one copy of any publication from the public portal for the purpose of private study or research.

- You may not further distribute the material or use it for any profit-making activity or commercial gain

- You may freely distribute the URL identifying the publication in the public portal.

If the publication is distributed under the terms of Article 25fa of the Dutch Copyright Act, indicated by the "Taverne" license above, please follow below link for the End User Agreement:

www.tue.nl/taverne

Take down policy

If you believe that this document breaches copyright please contact us at:

openaccess@tue.nl

providing details and we will investigate your claim. 


\title{
Formation of InAs wetting layers studied by cross-sectional scanning tunneling microscopy
}

\author{
P. Offermans, ${ }^{\text {a) }}$ P. M. Koenraad, R. Nötzel, and J. H. Wolter \\ Department of Applied Physics, Eindhoven University of Technology, P.O. Box 513, 5600 MB Eindhoven, \\ The Netherlands \\ K. Pierz \\ Physikalisch-Technische Bundesanstalt, Bundesallee 100, 38116 Braunschweig, Germany
}

(Received 13 May 2005; accepted 29 July 2005; published online 6 September 2005)

\begin{abstract}
We show that the composition of (segregated) InAs wetting layers (WLs) can be determined by either direct counting of the indium atoms or by analysis of the outward displacement of the cleaved surface as measured by cross-sectional scanning tunneling microscopy. We use this approach to study the effects of the deposited amount of indium, the InAs growth rate, and the host material on the formation of the WLs. We conclude that the formation of (segregated) WLs is a delicate interplay between surface migration, strain-driven segregation, and the dissolution of quantum dots during overgrowth. @ 2005 American Institute of Physics. [DOI: 10.1063/1.2042543]
\end{abstract}

The formation of InAs wetting layers (WLs) has attracted relatively little attention compared to quantum dot (QD) formation. ${ }^{1-3}$ In the simple picture of StranskiKrastanov growth, after the buildup of a critical amount of strain, two-dimensional layer growth is followed by QD formation. It has become increasingly clear, however, that such a simple picture is far from reality. Recently, In incorporation during pseudomorphic InAs/GaAs growth and QD formation were observed by in situ stress measurements. ${ }^{4}$ In this work, we study the segregation of InAs WLs by either directly counting the indium atoms or by analysis of the outward displacement of the cleaved surface as measured by cross-sectional scanning tunneling microscopy (X-STM).

By cleaving the sample containing the WLs, the crosssectional surface of the segregated InAs WLs is exposed, and releases its strain due to the lattice mismatch between the InAs and the surrounding GaAs (or AlAs) matrix, which results in an outward displacement of the cleaved surface. ${ }^{5}$ This can be measured with X-STM at high negative sample voltages $(<-2 \mathrm{~V})$, where the electronic contribution to the contrast in the image is minimized. ${ }^{6}$ By modeling the indium segregation, the outward displacement of the segregated WL can be calculated by integration of the analytical expression derived by Davies ${ }^{5}$ for the outward displacement of a cleaved quantum well. Several models for indium segregation have been proposed. ${ }^{7-10}$ We use the phenomenological model of Muraki et al. ${ }^{8}$, which has been shown to describe the indium composition $x(n)$ of InAs WLs well: ${ }^{3}$

$$
x(n)= \begin{cases}0, & n<1 \\ \left(1-R^{n}\right), & 1 \leqslant n \leqslant N, \\ \left(1-R^{N}\right) R^{n-N}, & n>N\end{cases}
$$

where $n$ is the monolayer (ML) index, $N$ is the total amount of deposited indium, and $R$ is the indium segregation coefficient. $N$ and $R$ are determined by fitting the calculated relaxation profile to the measured relaxation profile.

The WLs were grown by molecular-beam epitaxy on doped GaAs (100) wafers. In Sample A, three different sets of WLs were grown at $495{ }^{\circ} \mathrm{C}$ by deposition of $1.5 \mathrm{ML}, 2.0$

\footnotetext{
${ }^{a)}$ Electronic mail: p.offermans@tue.nl
}

ML, and 2.5 ML of InAs, respectively, at a growth rate of $0.1 \mathrm{ML} / \mathrm{s}$. Each layer was repeated two times, separated by a $50 \mathrm{~nm} \mathrm{GaAs}$ buffer layer, also grown at $495^{\circ} \mathrm{C}$. A growth interruption of $10 \mathrm{~s}$ was applied after the growth of each layer. No dot formation was observed for the layers with 1.5 ML indium deposition. In Sample B, two sets of WLs were grown at $480{ }^{\circ} \mathrm{C}$ by deposition of $2.0 \mathrm{ML}$ of InAs at a high and a low growth rate of $0.1 \mathrm{ML} / \mathrm{s}$ and $0.01 \mathrm{ML} / \mathrm{s}$, respectively. Each layer was repeated two times and capped by a 20 $\mathrm{nm} \mathrm{GaAs}$ layer grown at $480{ }^{\circ} \mathrm{C}$, followed by a $30 \mathrm{~nm}$ GaAs layer grown at $580{ }^{\circ} \mathrm{C}$. A growth interruption of $10 \mathrm{~s}$ was applied after the growth of each layer. In Sample C, one set of InAs layers was grown in GaAs while a second set was grown in AlAs barriers. The InAs layers were grown at $500{ }^{\circ} \mathrm{C}$ by deposition of $1.9 \mathrm{ML}$ of InAs in a cycled way, i.e., with a $3 \mathrm{~s}$ pause after each deposition of $0.25 \mathrm{ML}$, at a growth rate of $0.043 \mathrm{ML} / \mathrm{s}$. The following layer sequence was used: $20 \mathrm{~nm} \mathrm{GaAs} / 1.9 \mathrm{ML}$ InAs/40 nm GaAs/1.9 ML InAs/40 nm GaAs/50 nm GaAs(doped $\left.1 \times 10^{18} \mathrm{~cm}^{-2}\right) /$ $20 \mathrm{~nm} \mathrm{GaAs} / 4 \times(20 \mathrm{~nm}$ AlAs/1.9 ML InAs/20 nm AlAs/ $40 \mathrm{~nm}$ GaAs). To reduce interface roughness, the bottom AlAs barriers were grown at $600{ }^{\circ} \mathrm{C}$ followed by a growth interruption prior to InAs deposition.

Sample A was used to study the effect of the amount of indium deposition on the WL formation. We measured the relaxation profiles of the WLs and fitted these with calculated relaxation profiles, by adjusting the fit parameters $N$ and $R$. The resulting segregation profiles were verified by directly counting the number of indium atoms in the WL as a function of distance in growth direction. For the counting procedure, we selected four high-quality images of each layer, such as the one shown in Fig. 1. The relaxation and segregation profiles are shown in Fig. 2. In all three cases, we find an excellent agreement between the indium profile determined from the outward relaxation of the surface, and the direct counting procedure. For the 1.5 ML WL, the measured amount of indium $N$ corresponds to the deposited amount, since no indium has gone into dot formation. For the 2.0 ML and 2.5 ML WLs, however, we find a clear indium enrichment of the WL, despite dot formation.

In Stranski-Krastanov growth mode, strain builds up until the critical amount of indium for dot formation is 


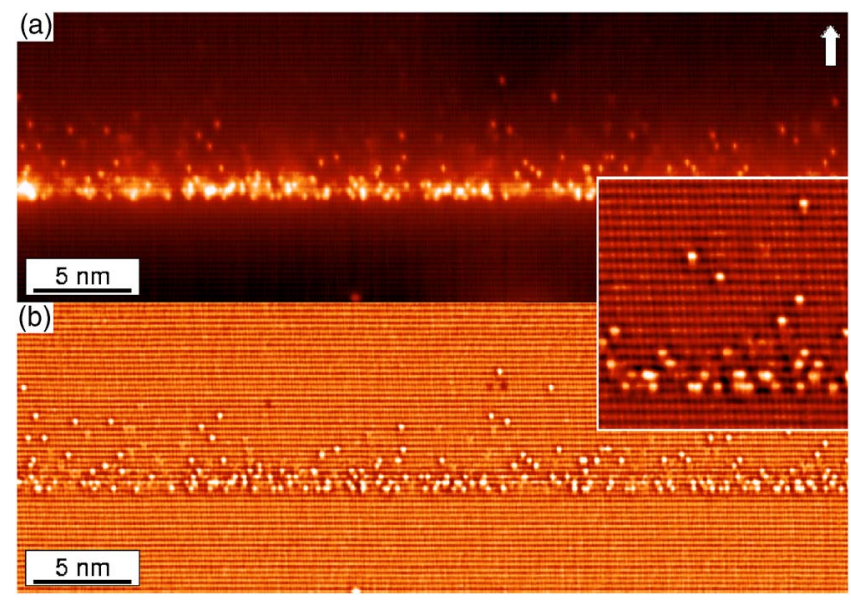

FIG. 1. (Color online) (a) Empty states X-STM image of a segregated 2.0 ML InAs WL. The arrow indicates the growth direction. (b) The same image treated with a high-pass Fourier filter. The inset shows an enlarged view of part of the image.

deposited. ${ }^{11}$ It has been shown that only part of the deposited amount of indium contributes to the strain, by incorporation into the lattice, while the remaining indium forms a floating layer on the surface. ${ }^{4}$ During dot formation, part of the floating indium is transferred by lateral mass transport to the dots. The amount of indium that remains in the dots, however, is strongly reduced by the capping process, which dissolves the top of the dots back into the WL. ${ }^{12}$ The dissolved indium adds to the remaining floating indium, and is eventually incorporated into the lattice during continued capping.

We used Sample B to study the effect of a reduced growth rate on the WL formation. It is known that a reduced growth rate leads to an increased QD size and a reduced QD
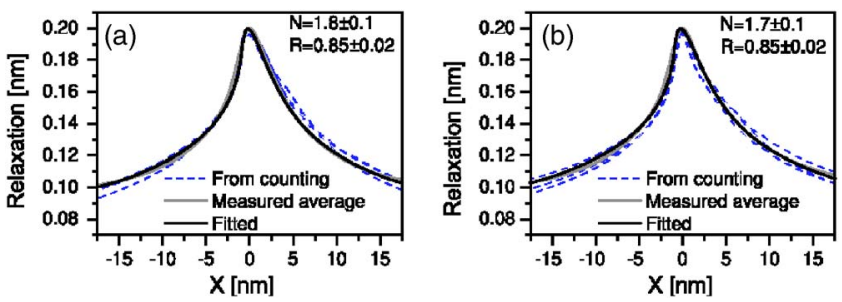

FIG. 3. (Color online) Measured and fitted relaxation profiles of the high (a) and low (b) growth rate InAs WLs of Sample B. The dashed lines indicate the relaxation profiles calculated directly from counted segregation profiles.

density. However, it is not a priori clear how this will affect the formation of the segregated WL in the buried structure. In Fig. 3, we show the average measured and calculated relaxation profiles of the InAs WLs of Sample B. The dashed lines indicate the relaxation profiles calculated directly from indium atom counting using different images. We find that the high $(0.1 \mathrm{ML} / \mathrm{s})$ and low $(0.01 \mathrm{ML} / \mathrm{s})$ growth rate InAs WLs can be described by the same parameters within errors. However, as expected, there is a marked difference in the size of the QDs, shown in Figs. 4(a) and 4(b). Whereas the QD grown at the high growth rate appears as a rather flat disklike shape with a height of $3 \mathrm{~nm}$, the QDs grown at low rate show an indium distribution with a reversed truncated cone shape ${ }^{13}$ with a height of $5.4 \mathrm{~nm}$.

We studied the effect of the host material by analyzing the segregation of InAs WLs grown in the AlAs barriers of Sample C, and comparing this to the segregation of InAs WLs grown-under the same growth conditions-in a GaAs matrix. It has been shown that QD formation in the InAs/AlAs system is kinetically limited due to a reduced
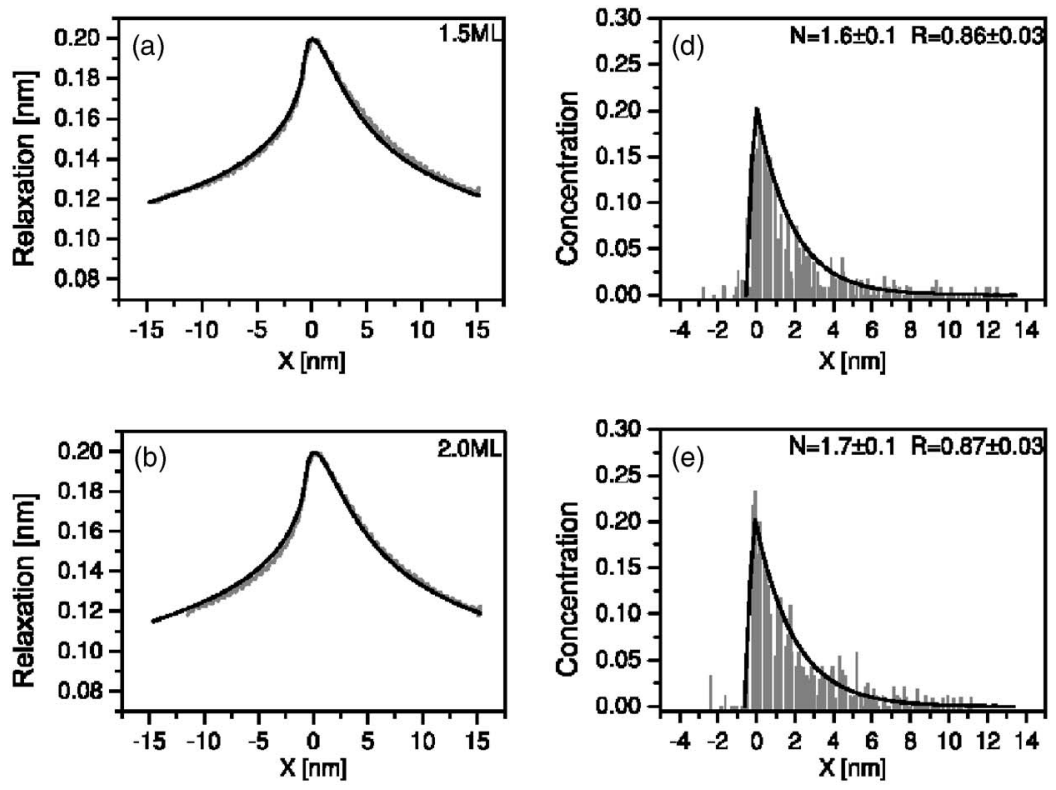

FIG. 2. Measured and fitted relaxation profiles of the 1.5 ML (a), 2.0 ML, (b), and 2.5 ML (c) InAs WLs of Sample A. The black curves in (d), (e), and (f) show the segregation profiles corresponding to the fitted relaxation profiles in (a), (b), and (c). The columns indicate the counted indium concentration in the WL as a function of distance $X$ in the growth direction.
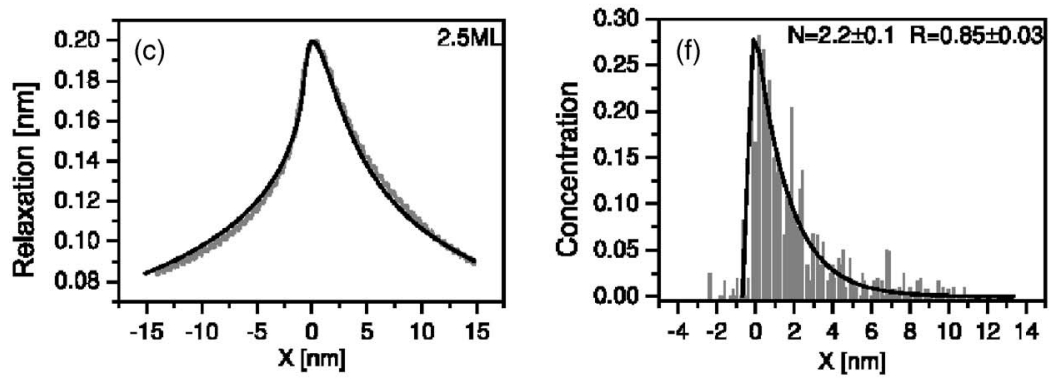

Downloaded 11 Oct 2007 to 131.155.108.71. Redistribution subject to AIP license or copyright, see http://apl.aip.org/apl/copyright.jsp 

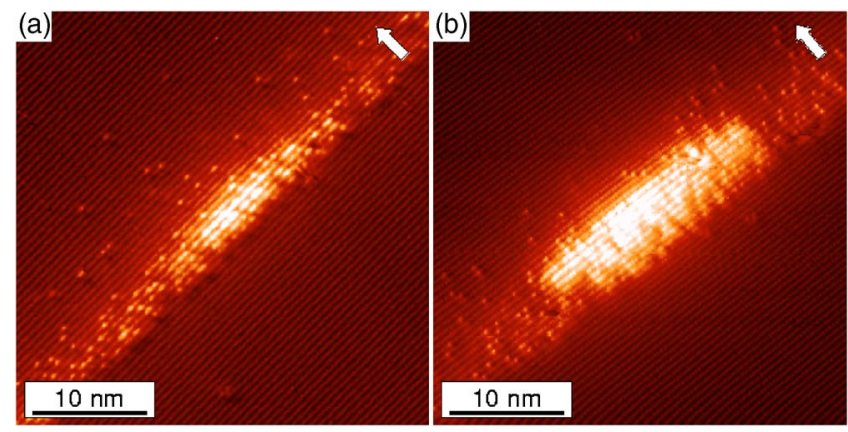

FIG. 4. (Color online) X-STM images of typical QDs found in the high (a) and low growth rate WLs (b). The arrow indicates the growth direction.

lateral In migration on the AlAs surface, because of the larger $\mathrm{Al}-\mathrm{In}$ bond strength. ${ }^{14}$ Recently, we reported on the marked differences in the structural properties of the dots grown in GaAs and AlAs. ${ }^{15}$ Figure 5 shows the averaged measured and fitted relaxation profiles. We find that the vertical indium segregation in AlAs and GaAs can be described by almost the same parameters, in agreement with Ref. 2 . This indicates that, in contrast to the lateral In migration, the vertical indium segregation is strain driven rather than determined by the chemical bond strength.

It is known that vertical indium segregation is reduced at lower growth temperatures. ${ }^{16} \mathrm{We}$ have reported that reducing the growth temperature to $300{ }^{\circ} \mathrm{C}$ after capping of the WLs with 3 MLS of GaAs leads to a dramatic reduction of the indium segregation. ${ }^{12}$ However, such a capping procedure also leads to the almost complete dissolution of the QDs into the capping layer due to their partial coverage.

Another drastic example of the effects of partial capping is the formation of quantum rings (QRs). QRs can be grown by the partial capping of QDs with $2 \mathrm{~nm}$ of GaAs and subsequent annealing. ${ }^{17}$ Recently, we observed that during this process, a second layer of indium accumulates on the surface of the capping layer, which is due to vertical segregation of indium from the WL and to lateral migration on the surface of indium atoms that have been expelled from the QDs during QR formation. ${ }^{18-21}$ After continued capping, the second layer of indium, itself, forms a segregated indium distribution.

Finally, we show in Fig. 6 an overview image of the WLs of Sample B. Surprisingly, one of the layers showed a shallow V-groove in which a QD was formed. The V-groove was unintentionally created on the GaAs substrate. It can clearly be seen that a large amount of indium atoms have accumulated in the V-groove. By comparing the extent of the indium segregation inside and outside of the V-groove, it can be seen that during GaAs overgrowth, the indium segrega-
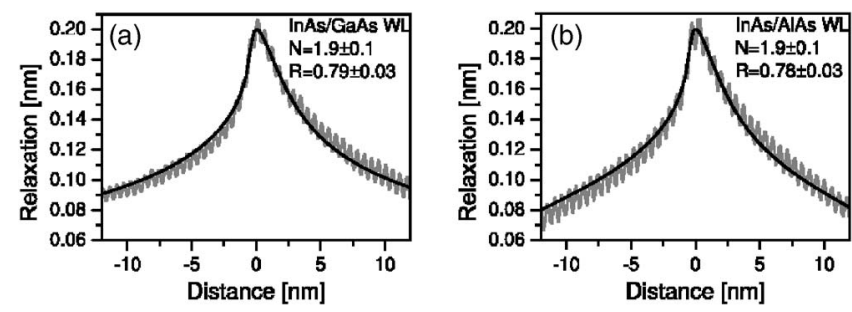

FIG. 5. Measured and fitted relaxation profiles of the segregated InAs WLs in GaAs (a) and AlAs (b).

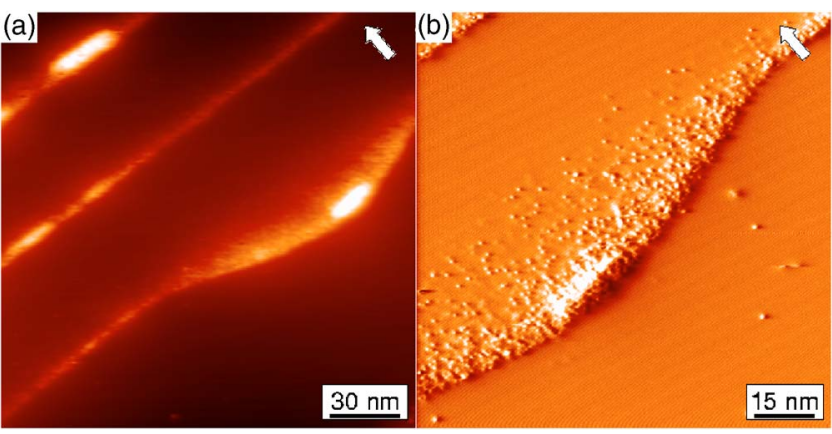

FIG. 6. (Color online) (a) X-STM overview image showing a shallow V-groove in one of the layers of Sample B. (b) X-STM current-image showing an enlarged view of the $\mathrm{V}$-groove. The arrow indicates the growth direction.

tion and migration facilitates a rapid planarization of the growth front, in the presence of indium atom accumulation in the V-groove.

To summarize, we have shown that the composition of (segregated) InAs WLs can be determined by either directly counting the indium atoms or by analysis of the outward displacement of the cleaved surface as measured by X-STM. We used this approach to study the effects of the deposited amount of indium, the InAs growth rate, and the host material on the formation of the WLs. We conclude that the formation of (segregated) WLs is a delicate interplay between surface migration, strain-driven segregation, and the dissolution of QDs during overgrowth.

${ }^{1}$ M. A. Migliorato, A. G. Cullis, M. Fearn, and J. H. Jefferson, Phys. Rev. B 65, 115316 (2002).

${ }^{2}$ M. Schowalter, A. Rosenauer, D. Gerthsen, M. Arzberger, M. Bichler, and G. Abstreiter, Appl. Phys. Lett. 79, 4426 (2001).

${ }^{3}$ A. Rosenauer, D. Gerthsen, D. V. Dyck, M. Arzberger, G. Böhm, and G. Abstreiter, Phys. Rev. B 64, 245334 (2001).

${ }^{4}$ J. P. Silveira, J. M. García, and F. Briones, Appl. Surf. Sci. 188, 75 (2002).

${ }^{5}$ J. H. Davies, D. M. Bruls, J. W. A. M. Vugs, and P. M. Koenraad, J. Appl. Phys. 91, 4171 (2002).

${ }^{6}$ R. M. Feenstra, Physica B 273, 796 (1999).

${ }^{7}$ J. M. Moison, C. Guille, F. Houzay, F. Barthe, and N. V. Rompay, Phys. Rev. B 40, 6149 (1989)

${ }^{8}$ K. Muraki, S. Fukatsu, Y. Shiraki, and R. Ito, Appl. Phys. Lett. 61, 557 (1992).

${ }^{9}$ N. Grandjean, J. Massies, and M. Leroux, Phys. Rev. B 53, 998 (1996).

${ }^{10}$ O. Dehaese, X. Wallart, and F. Mollot, Appl. Phys. Lett. 66, 52 (1995).

${ }^{11}$ A. G. Cullis, D. J. Norris, T. Walther, M. A. Migliorato, and M. Hopkinson, Phys. Rev. B 66, 081305(R) (2002).

${ }^{12}$ Q. Gong, P. Offermans, R. Nötzel, P. M. Koenraad, and J. H. Wolter, Appl. Phys. Lett. 85, 5697 (2004).

${ }^{13}$ A. Lenz, R. Timm, H. Eisele, C. Hennig, S. K. Becker, R. L. Sellin, U. W. Pohl, D. Bimberg, and M. Dähne, Appl. Phys. Lett. 81, 5150 (2002).

${ }^{14}$ K. Pierz, Z. Ma, U. F. Keyser, and R. J. Haug, J. Cryst. Growth 249, 477 (2003).

${ }^{15}$ P. Offermans, P. Koenraad, J. Wolter, K. Pierz, M. Roy, and P. Maksym, Physica E (Amsterdam) 26, 236 (2005).

${ }^{16}$ Y. C. Kao, F. G. Celli, and H. Y. Liu, J. Vac. Sci. Technol. B 11, 1023 (1993).

${ }^{17}$ D. Granados and J. M. García, Appl. Phys. Lett. 82, 2401 (2003).

${ }^{18}$ L. G. Wang, P. Kratzer, M. Scheffler, and Q. K. K. Liu, Appl. Phys. A: Mater. Sci. Process. 73, 161 (2001).

${ }^{19}$ Z. R. Wasilewski, S. Fafard, and J. P. McCaffrey, J. Cryst. Growth 201, 1131 (1999).

${ }^{20}$ E. Steimetz, T. Wehnert, H. Kirmse, F. Poser, J.-T. Zettler, W. Neumann, and W. Richter, J. Cryst. Growth 221, 592 (2000).

${ }^{21}$ A. Lenz, H. Eisele, R. Timm, S. K. Becker, R. L. Sellin, U. W. Pohl, D. Bimberg, and M. Dähne, Appl. Phys. Lett. 85, 3848 (2004). 